\title{
Reviews
}

\section{Treatment of Mechanical Valve Thrombosis during Pregnancy}

\author{
Calvin Choi, m.D., Scott Midwall, m.D., Peter Chaille, M.D., C. R. Conti, M.D., macc \\ Division of Cardiovascular Medicine, University of Florida College of Medicine, Gainesville, Florida, USA
}

\section{Summary}

Pregnant patients with mechanical valves require anticoagulation. The risk of bleeding and embryopathy associated with oral anticoagulation must be weighed against the risk of valve thrombosis. In the presence of a mechanical valve thrombosis, an appropriate treatment modality must be selected, as it is critical for the health of mother and fetus. In this review, we present a pregnant patient with mechanical valve thrombosis (MVT) who underwent thrombolytic therapy, subsequent anticoagulation according to available guidelines, and delivered a healthy baby at full term.

Key words: mechanical valve thrombosis, anticoagulation, thrombolysis, pregnancy

Clin. Cardiol. 2007; 30: 271-276.

(c) 2007 Wiley Periodicals, Inc.

\section{Introduction}

The hypercoagulable state during pregnancy increases the incidence of mechanical valve thrombosis (MVT). For patients with a mechanical prosthetic valve, the incidence of thromboembolism during pregnancy is estimated from 7 to $23 \%$ and about half of these cases are MVT. $^{1}$

Address for reprints:

C. R. Conti, M.D., MACC

Division of Cardiovascular Medicine

University of Florida College of Medicine

PO Box 100277

Gainesville, FL 32610-0277, USA

e-mail: richard.conti@medicine.ufl.edu

Received: June 2, 2006

Accepted: June 30, 2006

Published online in Wiley InterScience

(www.interscience.wiley.com).

DOI: $10.1002 / \mathrm{clc} .20054$

(C) 2007 Wiley Periodicals, Inc.

\section{Illustration Case}

A 14-week pregnant, 36-year-old female presented with a one-day history of acute, persistent dyspnea. Past medical history was significant for congenital Ltransposition of the great vessels, ventricular inversion, and Epstein's anomaly involving the tricuspid valve. At age 15, she underwent pacemaker implantation and surgical repair of Epstein's anomaly with St. Jude mechanical valve in systemic atrioventricular position. Coumadin was electively discontinued prior to pregnancy, and subcutaneous heparin was initiated.

At presentation, her vital signs were: temperature 36.3 Celsius, heart rate 108 beats per min, systolic blood pressure $97 \mathrm{mmHg}$, diastolic blood pressures $68 \mathrm{mmHg}$, respiratory rate 35 breaths per min., and oxygen saturation $96 \%$ with supplemental oxygen. On physical examination, she had elevated jugular venous distention, bibasilar pulmonary rales, mild hepatojugular reflux, and trace bilateral edema to the knee. Cardiovascular examination revealed regular rhythm, muffled first heart sound, grade II/VI systolic murmur in left lower sternal border without rubs or gallops, point of maximal impulse was nondisplaced, and distal pulses were equal, intact and bounding. Laboratory and diagnostic study results were as follows:

- NT-pro B-type natriuretic peptide $1684 \mathrm{pg} / \mathrm{mL}$, troponin $\mathrm{T}$ less than $0.03 \mathrm{ng} / \mathrm{mL}$, creatine kinase $(\mathrm{CK})$ less than $30 \mathrm{U} / \mathrm{L}, \mathrm{CK}-\mathrm{MB} 1.5 \mathrm{ng} / \mathrm{mL}$, international normalized ratio (INR) 1, partial thromboplastin time 28 seconds.

- Chest radiograph: Pulmonary vascularity consistent with pulmonary edema.

- Electrocardiogram: No ischemic changes.

- Lower extremity duplex: No deep venous thrombosis.

- Fluoroscopy (Fig. 1): One leaflet of mechanical prosthetic valve with full range of motion and the other with minimal movement.

- Transthoracic echocardiogram (Fig. 2): Mechanical atrioventricular valve mean gradient of 28 $\mathrm{mmHg}$ and velocity of $3.6 \mathrm{~m} / \mathrm{s}$. No pericardial effusion or wall motion abnormalities.

- Fetal ultrasound: Normal gestation. 

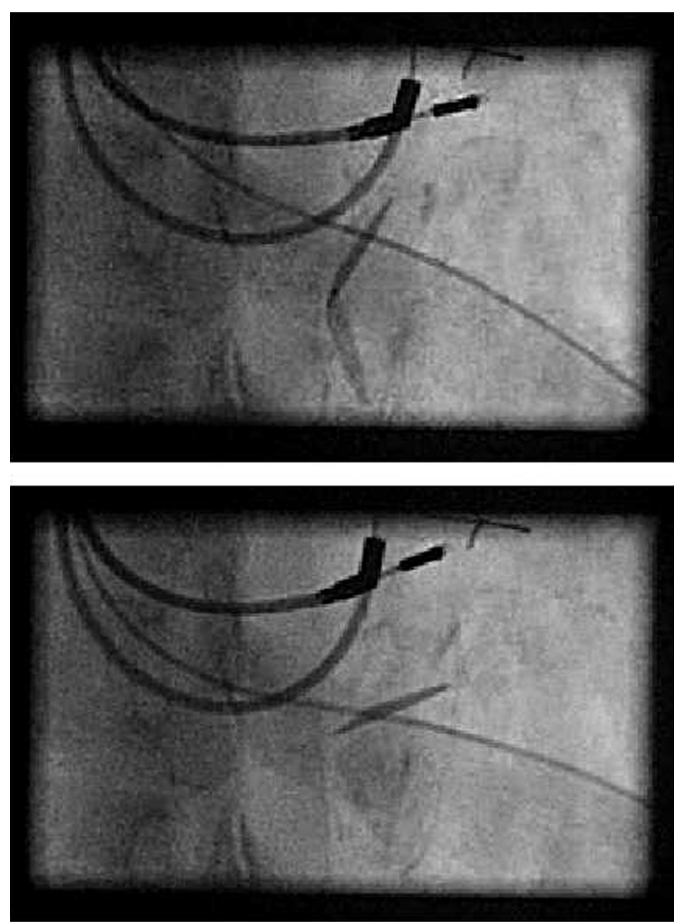

FIG. 1 One leaflet of mechanical prosthetic valve with full range of motion and the other with minimal movement.

The patient received recombinant tissue plasminogen activator as a $10 \mathrm{mg}$ intravenous bolus and 90 mg over $2 \mathrm{~h}$ with subsequent resolution of dyspnea. Crisp first heart sound was restored on cardiac auscultation, and mechanical atrioventricular valve mean gradient improved (Fig. 3). Thrombolytic therapy was complicated by a left lower extremity thromboembolism requiring thromboembolectomy. She recovered without further complications. The patient was anticoagulated with intravenous heparin during the hospitalization and discharged home with coumadin for the remainder of her pregnancy.

At 37 weeks of gestation, coumadin was discontinued, and the patient underwent an elective cesarian section on anticoagulation with intravenous heparin. She delivered a healthy baby. Her postoperative course was complicated by a subfascial hematoma that required blood transfusions and evacuation. Fortunatly, both mother and infant were discharged home in stable condition.

\section{Diagnosis}

MVT can best be diagnosed with fluoroscopy, since valve motion and opening/closing angles can be easily determined. ${ }^{2}$ Transthoracic echocardiogram with Doppler provides hemodynamics, valve gradient and area, and visualization of the valve. However, normal mechanical prosthetic valve gradient should be considered since different types of mechanical prosthetic valve accommodate variable valve gradients. ${ }^{3}$ In addition, transthoracic echocardiogram may be useful in detecting thrombus on the ventricular surface of the prosthesis, whereas transesophageal echocardiogram may enable detection of thrombus on the atrial surface of the prosthesis. ${ }^{4,5}$ Moreover, transesophageal echocardiogram is useful in determining thrombus burden. This is important since thrombus size is proportional to the risk of embolization and complications. ${ }^{6}$

\section{Treatment of Mechanical Valve Thrombosis}

The following applies to the general population unless stated otherwise. Accepted treatment modalities include: thrombolysis, valve replacement, and thrombectomy. For patients presenting with New York Heart Association (NYHA) functional class I through III and IV, the surgical mortality rates are $4.7 \%$ and $17.5 \%$, respectively. ${ }^{7}$

On recent meta-analysis, the overall clinical success rate for left-sided MVT treated with thrombolysis was reported as $72 \% .^{8}$ Clinical success was defined as resolution of thrombus and/or valvular obstruction indicated by increased leaflet movement to $90 \%$ of normal or clinical improvement without major complications. ${ }^{8}$ Clinical success correlated with NYHA classification, with best prognosis associated with class I. NYHA class I, II, III and IV had a clinical success rate of $100 \%, 90.9 \%$, $73.8 \%$ and $65.2 \%$, respectively. ${ }^{8}$ Clinical success was higher in aortic position than in mitral position $(83.3 \%$ vs. $67.2 \%){ }^{8}$ However, duration of symptoms, valve type, time elapsed from valve replacement to lytic therapy, choice of thrombolytic agent, and adequacy of anticoagulation at initial presentation were not contributing factors for clinical success. ${ }^{8}$

The overall mortality rate associated with lytic therapy was $9.9 \%$; the highest rates were observed in NYHA class III and IV with $11.9 \%$ and $13 \%$, respectively. ${ }^{8}$ The overall mortality rate associated with lytic therapy failure was $29.5 \% .^{8}$ Mechanical prosthetic valve reoperation was performed in $9.3 \%$ of patients who failed lytic therapy and the operative mortality in this group was $17.6 \% .^{8}$ The incidence of permanent neurological deficit due to cerebral embolism, transient cerebral embolism, peripheral embolism, and major hemorrhage were $3.3 \%$, $4.9 \%, 4.4 \%$, and $6 \%$, respectively. ${ }^{8}$ In addition, there was an association between increasing lytic therapy complications and the severity of heart failure symptoms. NYHA class I, II, III, and IV had overall complication rates of $10 \%, 13.6 \%, 16.6 \%$, and $30.4 \%$, respectively. ${ }^{8}$ Moreover, the incidence of recurrent MVT after successful treatment was $19.5 \%$, and there was no correlation between valve types or location and the recurrence rate. ${ }^{8}$ Furthermore, there was no difference in clinical success rate between initial MVT and recurrent MVT. ${ }^{8}$

On the basis of the meta-analysis data, lytic therapy is considered a first-line treatment option in MVT. Severity of heart failure symptoms is associated with worsening 


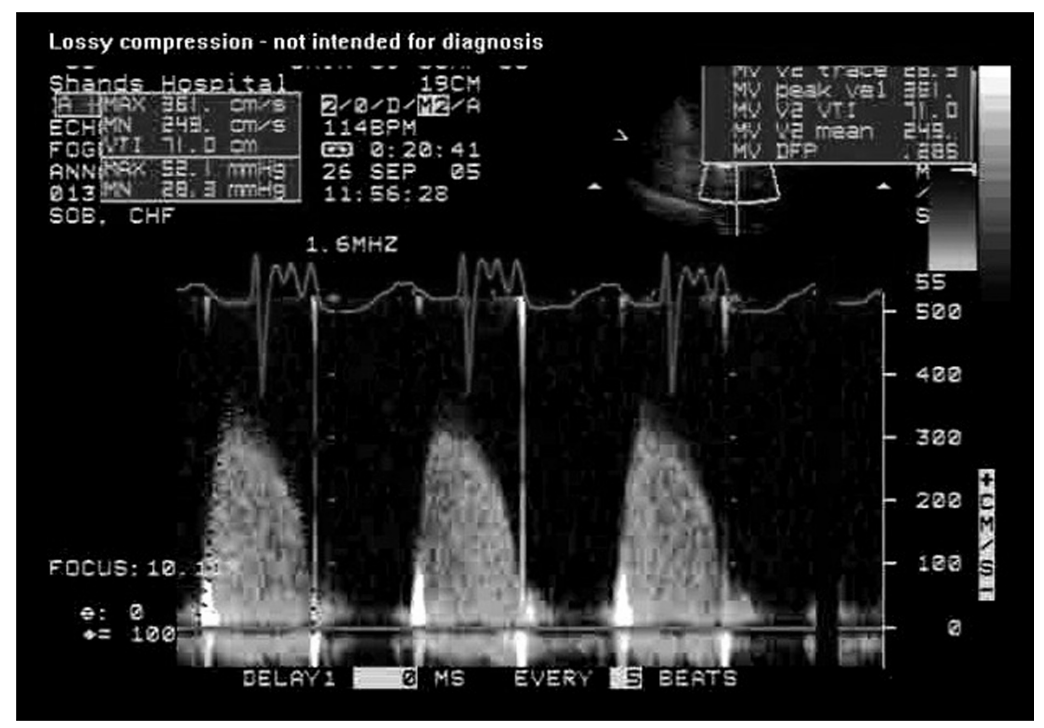

FIG. 2 Mechanical atrioventricular valve mean gradient of $28 \mathrm{mmHg}$ and velocity of $3.6 \mathrm{~m} / \mathrm{s}$. No pericardial effusion or wall motion abnormalities.

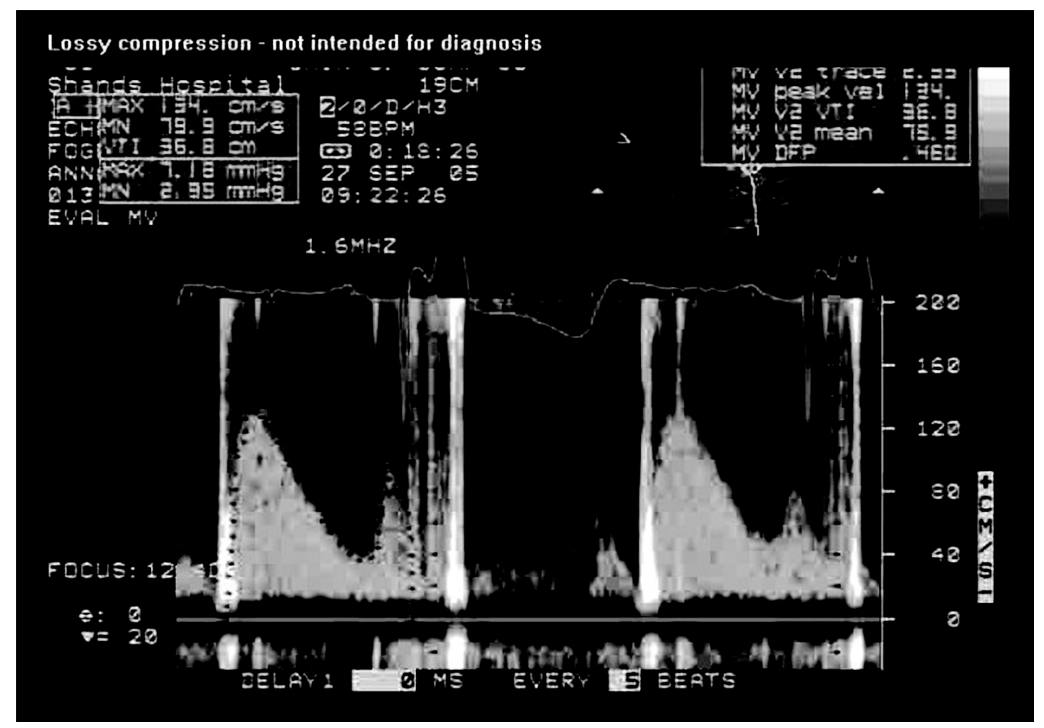

FIG. 3 Improved mechanical atrioventiricular valve mean gradient to $3 \mathrm{mmHg}$ and velocity to $1.3 \mathrm{~m} / \mathrm{s}$.

lytic therapy complications/mortality and surgical mortality. Because of technical challenges, prolonged hospitalization, and debilitation, surgery should be pursued after other options have been exhausted. The indications for surgery are: obstruction due to endocarditis, abscess, large thrombi, mobile mass, and failure of thrombolytic therapy. ${ }^{5}$

During pregnancy, lytic therapy is considered the firstline treatment for MVT in the absence of contraindications. ${ }^{1}$ In this population, lytic therapy was associated with $85 \%$ success rate, overall complication rate of $18 \%$, and mortality rate of $5.6 \% .^{9}$ Treatment modalities should be tailored for patients based upon hemodynamic status, comorbidities, and informed decision.

\section{Thrombolytic Therapy}

Streptokinase, urokinase, and recombinant tissue plasminogen activator are typical thrombolytic agents. Although they have similar efficacy, ${ }^{8}$ there are other factors to consider when choosing a thrombolytic agent. Streptokinase and urokinase are associated with lower cerebral hemorrhagic complication rates, and recombinant tissue plasminogen activator has the fastest onset and shortest half-life. ${ }^{10}$

Thrombolytic therapy duration is determined by treatment response. Lytic therapy can be administered for up to $72 \mathrm{~h}$ until hemodynamics improve, thrombus is lysed, and/or valve pressure gradient and area improve. 
Lytic therapy should be discontinued if there is no hemodynamic improvement after $24 \mathrm{~h}$. At that point, lytic therapy is deemed a failure and surgical intervention should be pursued. Surgical intervention can be considered $24 \mathrm{~h}$ after the lytic therapy or $2 \mathrm{~h}$ after lytic reversal with protease inhibitor. ${ }^{5}$

\section{Thrombolytic Therapy Complications}

Thromboembolism and hemorrhage are potential complications associated with lytic therapy.

In the presence of peripheral embolism, lytic therapy should be continued. However, should symptoms associated with peripheral embolism persist despite continued lytic therapy, embolectomy should be pursued. ${ }^{5}$ If neurological deficit is suspected, then lytic therapy should be discontinued and imaging should be obtained to evaluate hemorrhagic stroke. If the patient is found to have cerebral embolism, then anticoagulation therapy should be initiated. If a repeat imaging at 36-48 h does not show hemorrhagic conversion and MVT persists, then surgical intervention can be pursued $72 \mathrm{~h}$ following the stroke. ${ }^{5}$

If major hemorrhage is suspected, then lytic therapy should be discontinued. Moreover, if the bleeding site is noncompressible and/or internal, then fresh frozen plasma, prothrombin-complex-concentrate-containing Factor VII and/or lytic reversal with protease inhibitor may be required, along with blood transfusion. ${ }^{5}$

\section{Thrombolytic Therapy Contraindications}

Absolute contraindication for thrombolytic therapy are: internal bleeding, history of hemorrhagic stroke, recent cranial trauma or neoplasm, blood pressure greater than $200 / 120 \mathrm{mmHg}$, and diabetic hemorrhagic retinopathy. Relative contraindications for thrombolytic therapy are: recent (within 10 days) gastrointestinal bleeding, recent (within 10 days) puncture of noncompressible vessels, recent (within 2 months) nonhemorrhagic stroke, infective endocarditis, uncontrolled severe hypertension, large thrombus in left atrium or on prosthesis, recent (within 2 weeks) major operation or trauma, known bleeding diathesis, and previous exposure to streptokinase or anistreplase. ${ }^{5}$

\section{Anticoagulation during thrombolysis}

Anticoagulation during lytic therapy is not indicated. Coumadin should be discontinued but not actively reversed. Following completion of lytic therapy, heparin should be instituted until therapeutic goal with coumadin is reached (INR 2.5 to 3.5 ). ${ }^{11}$ Addition of aspirin (81 to $100 \mathrm{mg}$ per day) is recommended. ${ }^{12}$

\section{Anticoagulation for Pregnant Patients with Mechanical Prosthetic Valve}

The risks and benefits of heparin or coumadin use during the first trimester of pregnancy should be discussed with the patient. Coumadin use during 6 to 12 weeks of pregnancy in patients with mechanical prosthetic valve has been linked with gestational complications; e.g. premature birth, fetal growth retardation, spontaneous abortion (16.2-44\%), and embryopathy $(4.1 \%) .{ }^{13}$ Specifically, facial abnormalities (29\%), skeletal deformity (10\%), IQ less than 80 , and fetal hemorrhage comprise the major embryopathy. ${ }^{1}$

Coumadin use throughout pregnancy was associated with lowest all-cause maternal mortality rate and thromboembolism (1.8\% and $3.9 \%$, respectively). ${ }^{14}$ The incidence of spontaneous abortions and all-cause fetal demise (24-25\% and $27-43 \%$, respectively) were similar whether the mother was treated with coumadin alone, heparin alone or coumadin/heparin combinations. ${ }^{14}$ However, the incidence of congenital abnormalities were highest among mothers treated with coumadin throughout pregnancy $(6.4 \%$ vs. $0 \%$ when heparin was used throughout pregnancy). ${ }^{14}$ Major bleeding complications in mothers during pregnancy was $2.5 \%$, mostly during delivery, and all-cause maternal mortality during pregnancy was $2.9 \% .^{14}$

\section{Guidelines}

As per the American College of Cardiology and American Heart Association (ACC/AHA) guideline, for patients receiving coumadin for the duration of gestation, INR should be maintained between 2 and 3 along with low-dose aspirin. Because of the preponderance of premature birth and fetal hemorrhage, coumadin should be discontinued and heparin started at 35 to 36 gestational weeks. In the absence of significant bleeding, heparin should be resumed $4-6 \mathrm{~h}$ after the delivery and coumadin started. ${ }^{15}$ For the patients choosing heparin during the first trimester of gestation, ACC/AHA recommends the following (Table 1). ${ }^{15}$

American College of Chest Physicians (ACCP) recommends the following options for the management of anticoagulation during pregnancy in patients with mechanical prosthetic valve. In high-risk patients, lowdose aspirin (75-162 mg per day) should be added (Table 2). ${ }^{14}$

Elkayam et al. recommend the following regimen (Table 3). ${ }^{16}$

Low molecular weight heparin (LMWH) should be switched to intravenous unfractionated heparin (UFH) about $18-24 \mathrm{~h}$ prior to delivery. ${ }^{1} \mathrm{LMWH}$ has lower incidence of heparin-induced thrombocytopenia and heparininduced ostesporosis compared to UFH in patients receiving long-term heparin products. ${ }^{17,18}$ In addition, UFH or LMWH do not cross the placenta and are not secreted into breast milk, and coumadin does not cause anticolagulation in breast-milk fed babies. ${ }^{14,19-21}$ 
TABle 1 ACC/AHA Guidelines for Heparin Use During the First Trimister of Pregnancy. ${ }^{15}$

\begin{tabular}{lc}
\hline Risk group & Heparin goal \\
\hline $\begin{array}{l}\text { Low risk (no history of thromboembolism and newer } \\
\text { low-profile mechanical prosthetic valve) }\end{array}$ & $\begin{array}{l}\text { Subcutaneous unfractionated heparin (UFH) with } \\
\text { mid-interval activated partial thromboplastin time }\end{array}$ \\
$\begin{array}{l}\text { High risk (history of thromboembolism or an older } \\
\text { generation mitral mechanical prosthetic valve) }\end{array}$ & (PTT) goal of 2 to 3 times control value \\
& after dose) PTT goal of 2 to 3 times control value \\
\hline
\end{tabular}

TABle 2 ACCP Guidelines for Heparin Use During Pregnancy. ${ }^{14}$

\begin{tabular}{lc}
\hline Heparin Type & Goal \\
\hline $\begin{array}{l}\text { Subcutaneous UFH (17,500 to 20,000 units every 12 } \\
\text { h) throughout pregnancy }\end{array}$ & $\begin{array}{c}\text { Mid-interval PTT goal greater or equal to twice control } \\
\text { levels or anti-Xa activity at } 0.35 \text { to } 0.7 \text { IU/mL } \\
4 \text { hour post-injection anti-Xa activity of } 1 \text { to } 1.2 \mathrm{IU} / \mathrm{mL}\end{array}$ \\
$\begin{array}{l}\text { Low molecular weight heparin (LMWH) twice daily } \\
\text { throughout pregnancy }\end{array}$ & $\begin{array}{l}\text { As above } \\
\text { UFH or LMWH until the 13th week of gestation then } \\
\text { change to coumadin until the middle of the third } \\
\text { trimester and restart UFH or LMWH until delivery }\end{array}$ \\
\hline
\end{tabular}

TABLE 3 Recommendations of Elkayam et al. ${ }^{16}$

\begin{tabular}{|c|c|}
\hline Risk group & Heparin goal \\
\hline $\begin{array}{l}\text { Low risk (newer generation mechanical prosthetic } \\
\text { valve and/or mechanical prosthetic valve in aortic } \\
\text { position) }\end{array}$ & $\begin{array}{l}\text { Subcutaneous UFH (mid-interval PTT } 2 \text { to } 3 \text { times control } \\
\text { value) or LMWH (pre-dose anti-Xa of } 0.6 \mathrm{IU} / \mathrm{mL} \text { ) for } \\
12 \text { weeks, then coumadin (INR } 2.5 \text { to } 3 \text { ) until } 35 \\
\text { weeks, then subcutaneous UFH or LMHW as before } \\
\text { Subcutaneous UFH (mid-interval PTT } 2 \text { to } 3 \text { times control } \\
\text { value) or LMWH (pre-dose anti-Xa of } 0.6 \mathrm{IU} / \mathrm{mL} \text { ) } \\
\text { throughout pregnancy }\end{array}$ \\
\hline $\begin{array}{l}\text { High risk (older generation mechanical prosthetic valve } \\
\text { in mitral position, atrial fibrillation, history of } \\
\text { thromboembolism on anticoagulation) }\end{array}$ & $\begin{array}{l}\text { Coumadin (INR } 2.5 \text { to } 3.5 \text { ) for } 35 \text { weeks then } \\
\text { subcutaneous UFH (mid-interval PTT greater than } 2.5 \\
\text { times control value) or LMWH (pre-dose anti-Xa of } 0.7 \\
\text { IU/mL) with aspirin } 80 \text { to } 100 \mathrm{mg} \text { per day } \\
\text { Subcutaneous UFH (PTT } 2.5 \text { to } 3.5 \text { times control value) } \\
\text { or LMWH (pre-dose anti-Xa of } 0.7 \mathrm{IU} / \mathrm{mL} \text { ) for } 12 \\
\text { weeks then coumadin (INR } 2.5 \text { to } 3.5 \text { ) until } 35 \text { weeks, } \\
\text { then UFH or LMWH with aspirin } 80 \text { to } 100 \mathrm{mg} \text { per day }\end{array}$ \\
\hline
\end{tabular}

\section{Conclusion}

Pregnant patients with mechanical prosthetic valve presenting with symptoms of pulmonary congestion should have urgent fluoroscopy examination of the valve. If leaflets are malfunctioning, then thrombolytic therapy is appropriate if no contraindications are present.

\section{References}

1. Elkayam U, Bitar F. Valvular heart disease and pregnancy. Part II: prosthetic valves. J Am Coll Cardiol 2005;46(3):403-410

2. Montorsi P, Cavoretto D, Alimento M, Muratori M, Pepi M. Prosthetic mitral valve thrombosis: can fluoroscopy predict the efficacy of thrombolytic treatment? Circulation 2003;108(suppl 1):II79-II84
3. Hernandez-Vila E, Stainback RF, Angelini P, Krajcer Z. Thrombolytics and left-sided prosthetic valve thrombosis. Tex Heart Inst J 1998;25(2):130-135

4. Chambers J, Whaley A, Campbell S. Doppler echocardiography in massive left atrial thrombus before and after successful thrombolysis. Int J Cardiol 1988;18(3):427-432

5. Lengyel M, Fuster V, Keltai M, Roudaut R, Schulte HD, et al. Guidelines for management of left-sided prosthetic valve thrombosis: a role for thrombolytic therapy. J Am Coll Cardiol 1997;30(6): $1521-1526$

6. Roudaut R, Labbe T, Lorient-Roudaut MF, Gosse P, Baudet F, et al. Mechanical cardiac valve thrombosis. Is fibrinolyisis justified? Circulation 1992;86(suppl 5):II8-II15

7. Deviri E, Sareli P, Wisenbaugh T, Cronje SL. Obstruction of mechanical heart valve prostheses: clinical aspects and surgical management. J Am Coll Cardiol 1991;17(3):646-650

8. Koller PT, Arom KV. Thrombolytic therapy of left-sided prosthetic valve thrombosis. Chest 1995;108(6):1683-1689 
9. Tong AT, Roudaut R, Ozkan M, Sagie A, Shahid MS, et al. Prosthetic Valve Thrombolysis-Role of Transesophageal Echocardiography (PRO-TEE) Registry Investigators. Transesophageal echocardiography improves risk assessment of thrombolysis of prosthetic valve thrombosis: results of the international PRO-TEE registry. J Am Coll Cardiol 2004;43(1):77-84

10. Caceres-Loriga FM, Perez-Lopez H, Santos-Gracia J, MorlansHernandez K. Prosthetic heart valve thrombosis: Pathogenesis, diagnosis and management. Int J Cardiol 2005;110(1):1-6

11. Stein PD, Alpert JS, Copeland J, Dalen JE, Goldman S, et al. Antithrombotic therapy in patients with mechanical and biological prosthertic heart valves. Chest 1995;108(suppl 4):371S-379S

12. Turpie A, Gent M, Laupacis A, Latour Y, Gunstensen J, et al. A comparison of aspirin with placebo in patients with warfarin after heart-valve replacement. N Engl J Med 1993;329:524-529

13. Salazar E, Izaguirre R, Verdejo J, Mutchinick O. Failure of adjusted doses of subcutaneous heparin to prevent thromboembolic phenomena in pregnant patients with mechanical cardiac valve prostheses. J Am Coll Cardiol 1996;27(7):1698-1703

14. Bates SM, Greer IA, Hirsh J, Ginsberg JS. Use of Antithrombotic agents during pregnancy: the seventh ACCP Conference on Antithrombotic and Thrombolytic Therapy. Chest 2004;126(suppl 3): $627 \mathrm{~s}-644 \mathrm{~s}$

15. Bonow RO, Carabello B, DeLeaon AC Jr, Edmunds LH Jr, Fedderly $\mathrm{BJ}$, et al. ACC/AHA guidelines for the management of patients with valvular heart disease: a report of the American College of Cardiology/American Heart Association Task Force on practice guidelines (Committee on management of patients with valvular heart disease). J Am Coll Cardiol 1998;32:1486-1582

16. Elkayam U, Singh H, Irani A, Akhter MW. Anticoagulation in pregnant women with prosthetic heart valve. J Cardiovasc Pharmacol Ther 2004;9(2):107-115

17. Warkentin TE, Levine MN, Hirsh J, Horsewood P, Roberts RS, et al. Heparin-induced thrombocytopenia in patients treatd with lowmolecular-weight haparin or unfractionated heparin. $N$ Engl J Med 1995;332:1330-1336

18. Pettila V, Leinonen P, Markkola A, Hiilesmaa V, Kaaja R. Postpartum bone mineral density in women treated for thromboprophylaxis with unfractionated heparin or LMW heparin. Thromb Haemost 2002;87(2):182-186

19. Forestier F, Daffos F, Capella-Pavlovsky M. Low molecular weight heparin (PK 10169) does not cross the placenta during the second trimester of pregnancy: study by direct fetal blood sampling under ultrasound. Thromb Res 1984;34(6):557-560

20. Forestier F, Daffos F, Rainuat M, Toulemonde F. Low molecular weight heparin (CY 216) does not cross the placenta during the third trimester of pregnancy. Thromb Haemost 1987;57(2):234

21. Flessa HC, Klapstrom AB, Glueck MJ, Will JJ. Placental transport of heparin. Am J Obstet Gynecol 1965;93(4): $570-573$ 